\title{
A Corpus-based Study of the Discursive Construction of Corporate Identities by Chinese and American Banks
}

\author{
Xia Cheng | ORCID: 0000-0002-5346-498X \\ Lecturer, Ph.D, School of Languages and Communication Studies, \\ Beijing Jiaotong University, Beijing, China \\ xiacheng@bjtu.edu.cn \\ Xingsong Shi| ORCID: 0000-0002-8069-7156 \\ Professor, Ph.D, School of International Studies, University of International \\ Business and Economics, Beijing, China \\ xsongshi@126.com
}

\begin{abstract}
By taking the perspective of Social Constructivism and the Discourse-Historical Approach, and using the corpus linguistic tool Wmatrix, this study compares the discursive strategies adopted by Chinese and American banks in their construction of corporate identities. The research underlines the shared and unique features presented in prominent themes, communication strategies and lexical patterns. It is found that Chinese banks prefer to emphasise their historical development, industrial ranking and organisational structure to positively construct their identity as industry leaders, adopting a corporate ability strategy through the frequent usage of numbers and superlative adjectives. However, American banks tend to stress care for their employees, communities and environment. They prefer to use a corporate responsibility strategy to build their identity as social contributors through the frequent usage of performative verbs to exhibit specific corporate activities. This study may have practical implications for Chinese companies wishing to improve their international communication capability and may offer educational implications for Business English teaching.
\end{abstract}

\section{Keywords}

corporate identity - discursive strategies - discursive construction of identity 
Identity has been an area of concern for researchers in the humanities and social sciences, and has undergone a shift from a traditional essentialist approach to a social constructionist approach. The traditional view emphasises the social attributes of identity, believing identity to be relatively stable and the role played by individuals or groups in certain social relations, such as gender, age, race, position, etc. (Stryker, 1987). However, a social constructionist view holds that identity is not fixed. It is the result of continuous construction and dynamic negotiation in interactions (Bucholtz and Hall, 2005; Chen, 2014; PAD research group, 2016). By adopting a social constructionist approach, a large body of literature in linguistics has investigated the identity that is constructed in discourse. But, so far, existing research has focused a great deal of attention on national identity, ethnic identity, teacher identity, etc., with institutional identity being somewhat underexplored. As an important type of institutional identity, corporate identity is of great significance to the development of companies. It can influence the public's perception of the corporate image and the employees' recognition of corporate value, and then further affect a corporation's ability to obtain resources (Wu and Zhang, 2019). While practitioners have recognised the importance of corporate identity, relatively little work has examined how corporate identity is discursively constructed.

Previous studies on corporate identity can be traced back to the 199os. Most of these investigations, however, are conducted from the perspective of management and marketing to explore the strategic management of corporate identity (e.g., Balmer and Gray, 1999). It is understood that corporate communication is the most important element of corporate identity (Melewar, 2003). However, previous studies have not paid adequate consideration to how corporate identity is constructed through corporate discourse. Our research attempts to narrow this gap, by adopting a discourse analytical perspective to examine how corporate identity is communicated.

Against the background of China vigorously encouraging its companies to 'go global' and promote Chinese brands beyond China via the 'Belt and Road' initiative, discussing the discursive construction of corporate identity from a linguistic perspective is of great theoretical and practical significance, as it can have practical implications for corporations on how to enhance the recognition and acceptance of overseas stakeholders. In order to enrich studies on corporate identity construction, both theoretically and methodologically, the current study integrates linguistic approaches to conduct a comparative analysis of the discursive construction of corporate identities by Chinese and American banks, so as to deepen the understanding of the similarities and differences between 
Chinese and foreign corporate identity discourse and, subsequently, to provide corporations with helpful suggestions.

\section{Literature Review}

\subsection{Corporate Identity}

"Institutional identity" is defined as "the way an organization is commonly represented" (Christensen, 2008: 1016). Therefore, institutional discourse is inseparable in this self-representation. In line with the constructionist thinking, institutional identity is not static, but emerging and discursively constructed through the ongoing communication. As an important institutional identity, corporate identity in this study is defined as the self attributes discursively communicated in corporate communication. A handful of recent studies have focused on how institutional identities are discursively constructed, including university institutional identity (e.g., Chen, 2016, 2017), governmental identity communicated in publicity discourse (see Chai and Han, 2017) and corporate identity discursively constructed in annual reports or corporate social responsibility reports (e.g., Wu and Zhang, 2019; Liu and Wu, 2015). These studies have provided some insights for our study. More specifically, Chen (2016) proposed an analytical framework for comparing the discursive construction of institutional identity by Chinese and Western universities. This framework is based on the discourse-historical approach, integrating the macro analysis of historical context, the meso analysis of identity dimensions and the micro analysis of discursive strategies. Chen (2017) further enriched and refined the micro-level discursive strategies in the above research framework, revealing the commonalities and unique patterns present in institutional identity construction in different social cultural contexts. By referring to this study, $\mathrm{Wu}$ and Zhang (2019: 222) proposed an analytical framework for the discursive construction of corporate identities and compared the discursive strategies adopted by Huawei and Apple when constructing their identities in annual reports, respectively.

Based on Wu and Zhang's framework, our study adopts the discoursehistorical approach to compare how the corporate identities of Chinese and American banks are discursively constructed.

\subsection{Corporate Identities Discursively Constructed in Corporate Profiles}

Contrastive analysis of business genres in different cultures has received considerable attention in recent years. Most of these previous studies have been either comparing two comparable business reports in different cultures on, for 
example, Italian and English letters to shareholders (Garzone, 2004), English and German letters to shareholders (Böttger \& Bührig, 2004), or contrasting the original and translated business text (e.g. House, 2011), to explore some specific linguistic features like personal pronouns, meta discourse and linking words, or to examine the translation strategies. Although previous studies have discussed business communication in different cultures and provided strong evidence in companies' distinguished preferences in communication across cultures, far less attention has been paid to corporate identities discursively constructed through business communication and their detailed linguistic realizations. Even fewer studies look into this issue with a cross-cultural perspective, contrasting Chinese and western companies' identities communicated in business contexts. While Chinese companies are becoming more and more involved in international markets, how Chinese companies communicate their identities to the international audience deserves academic attention.

Regarding the business genres which communicate a corporate identity, a wide range of types have been identified in the literature, such as annual reports, corporate social responsibility reports, corporate websites, social media, corporate profiles, etc. Of these, corporate profiles are considered to be the main medium for constructing a corporate identity. A corporate profile provides a basic answer to 'who am I?', which generally consists of an introduction to the corporation's historical development, its business scope, corporate values, corporate social responsibilities, corporate strategies, award-winning and other business-related information. The information is disseminated under close scrutiny, and discursively and strategically presents the corporation to the public. Therefore, corporate profiles, as a tool for corporate branding, have attracted attention in previous studies (e.g., Pollach, 2005; Shi and Shan, 2019). For example, Pollach (2005) discussed the discursive strategies used by corporations to present themselves in their corporate profiles. An array of persuasive appeals was identified when constructing a credible identity, such as appeals to the credibility of sources, appeals to reason and appeals to emotions. Besides, other linguistic features, such as self-reference and audience address forms, were also adopted, to form and maintain a relationship with the public. Apart from the few studies mentioned above, the majority of previous studies on corporate profiles have focused on the quality of translation from the Chinese version of a corporate profile into English (e.g., Lu, 2019). Few studies have considered the discursive construction of corporate identity via self-representation in corporate profiles. In current society, English has been widely acknowledged as the lingua franca, thereby has been employed by Chinese companies as the primary choice for international business communication. Therefore, this study explores how Chinese companies communicate 
their corporate identities through corporate profiles on their official English websites, in contrast with the American counterparts.

\subsection{Wmatrix as a Significant Corpus Tool}

Regarding research methods, many previous studies have been carried out by either conducting a case study of a company's webpage or by qualitatively comparing the discursive identity presented by two different companies in several written business texts. For example, the PAD research group (2016) analysed how a British company communicated its identity via textual and multimodal discourse on its website. Few studies have employed a corpusbased approach to explore the linguistic patterns in large amounts of data. However, corpus tools can reduce researcher bias and facilitate the micro analysis of the linguistic features involved in identity construction (Baker, 2006; Chai and Han, 2017). Of these corpus tools, Wmatrix breaks through the limitation of the simple descriptive analysis of keyword frequency and can identify prominent semantic categories in texts (Rayson, 2008), which helps reveal the value system running through business discourse (Breeze, 2018). Given its automatic semantic tagging tool, it is not surprising that Wmatrix has been used to explore corporate communication. For example, Sun and Jiang (2014) used this tool to identify metaphors in the mission statements of Chinese and American corporations, and found that Chinese enterprises tend to portray themselves as competitors, while American corporations prefer to project themselves as responsible community members. Similarly, Breeze (2018) investigated the evaluative discourse employed in annual reports by using semantic tagging and found that companies from different sectors have different value preferences. For instance, financial companies tend to highlight the keyness of semantic area S1.2.5[tough, strong] to shape a dynamic and masculine image. These studies confirm the rationale behind, and the appropriateness of using the corpus tool Wmatrix to study corporate discursive identity.

\subsection{A Theoretical Framework for the Construction of Corporate Discursive Identity}

Inspired by the analytical framework proposed by Chen (2016), this paper adopts the discourse-historical approach as the theoretical framework. As an important branch of critical discourse analysis, discourse-historical analysis focuses on the mutual construction of discourse and society, that is, how discourse constructs social reality and how social reality affects discursive practice (Wodak, 2001).

The discourse-historical approach advocates that discourse should be placed in its social context to explore its social construction function from 
three dimensions: theme content, discursive strategies and linguistic means (Wodak, 2001: 72), and it has been widely used when studying the discursive construction of corporate identity. Following this analytical path, this paper proposes a research framework (as shown in Figure 1) involving the macro analysis of thematic preferences, the meso analysis of communication strategies and the micro analysis of linguistic features, in order to compare the discursive construction strategies adopted by Chinese and American banks and further reveal the identities communicated.

At the macro level, this study compares the main thematic differences in the corporate profiles of Chinese and American banks. In order to reduce human bias, this paper adopts the corpus tool Wmatrix to automatically identify key semantic areas, and then analyses the resulting collocations and concordance lines to obtain the main themes communicated by Chinese and American banks. Wodak (2001: 69) pointed out that when researchers use the discoursehistorical approach to explore a specific social problem, they should not only choose appropriate linguistic analytical perspectives and tools, but should also choose appropriate theories to interpret the results. At the macro level, Chinese

Analysis of Thematic Preferences

Semantic Areas

Themes Communicated

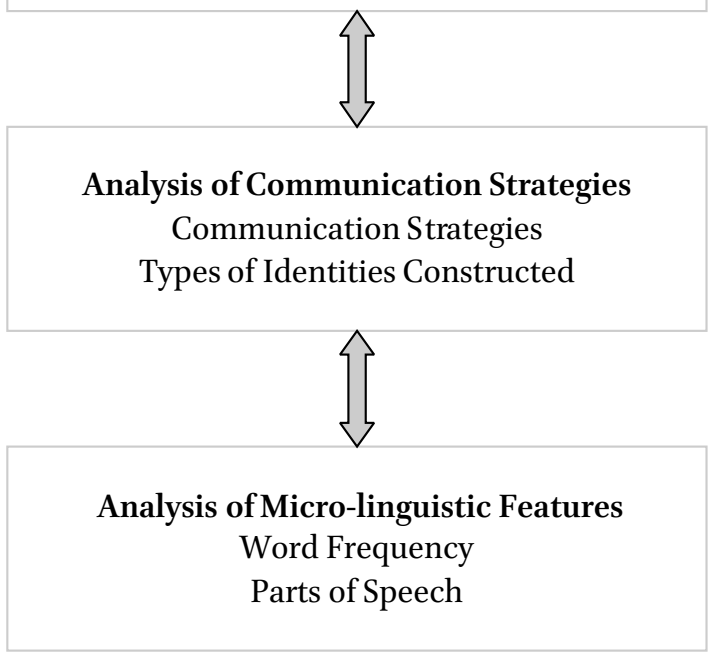

FIGURE 1 Analytical framework for the discursive construction of corporate identity 
and American cultures are the most direct social contexts for the discursive construction of corporate identity. Therefore, the study resorted to Hofstede's cultural dimension theory (2010) to analyze the possible impact of national cultural differences. Even though Hofstede's theory is not without flaws, it has been acknowledged as the most referred and testified cultural typology, especially in studies on intercultural business communication (Moura et al., 2016). Since this model has been criticized mainly for its validity in statistical analysis, to avoid this problem, the current study primarily relies on the model's analytical function to explore the intercultural reasons for different identity constructions.

At the meso level, Chen (2016) pointed out that a meso analysis needs "insight into the content of a corpus, induction and reflection, and combination of relevant discipline theories to form an analytical framework" (p. 33). The research object of this paper is corporate discourse, which falls within the context of business discourse. Therefore, this study, based on Kim and Rader's (2010: 6o) theoretical discussion on corporate communication strategies, forms three observation dimensions, namely, corporate ability strategy, corporate social responsibility strategy and hybrid strategy, to investigate the preferred communication style used in the construction of Chinese and American corporate identity. Corporate communication strategy in the current study is content-orientated, which can not only reflect macro themes communicated, but can also give an insight into micro-linguistic features, thus effectively connecting macro and micro analyses. According to Kim \& Rader (2010), corporations tend to create publics' different cognitive associations by communicating their expertise and ability in terms of products and services, or their social responsibility activities. A corporate ability strategy focuses on introducing products and services, corporate development, business scale, risk control capability, etc. It is aimed at enhancing the audience's rational cognition of corporate strength and expertise. For the most part, a corporate social responsibility strategy presents the corporation's fulfilled social responsibilities, such as care for its employees, environmental protection and community services, which helps to win the public's trust. A hybrid strategy indicates that companies not only attach importance to presenting corporate abilities, but also to communicating corporate social responsibilities. The above three communication strategies are important observation dimensions for examining corporate communication style and further revealing the main corporate identity types that are constructed.

Finally, a micro-linguistic analysis will combine the word list, parts of speech (POS) distribution and concordance lines that are automatically generated by 
Wmatrix to compare the actual forms that are used to realise corporate identity discourse at the micro level. Based on the above analytical framework, this paper aims to answer the following three questions:

1) Are there any differences in the semantic areas identified in the corporate profiles of Chinese and American banks? What themes are communicated at the macro level, respectively?

2) Are there any differences in the communication strategies deployed by Chinese and American banks for self-representation? What types of corporate identities are constructed, respectively?

3) Are there any differences in the micro-linguistic features of the corporate identity discourse used by Chinese and American banks?

\section{$3 \quad$ Research Methodology}

\subsection{Data Collection}

In this study, the rankings of Fortune 5oo Companies in China and the United States were selected as sample frames, respectively. To avoid the influence of industrial differences, we confined the sampled companies to one specific industry, i.e., listed banking companies. In the two rankings, 23 Chinese banks and 20 American banks are listed, which are representative of the banking industry in the two countries. Since the official English websites of two of the Chinese banks were still under construction and could therefore not be accessed, samples were finally limited to 21 Chinese banks and 20 American banks. Corporate profiles can give an insight into the discursive strategies used by corporations and can reveal the corporate identities that they intend to construct. Therefore, we collected text from the 'About us' section of the official English websites of the sampled Chinese companies and the official websites of the American companies. All extracted texts were assembled into two comparable corpora: the corpus of Chinese Corporate Identity Discourse (hereafter known as CCID) and the corpus of American Corporate Identity Discourse (hereafter known as ACID), respectively. As corporate websites are constantly updated, it should be noted that the data collection was conducted from June 17 th to June 19th, 2019. The CCID corpus has a total number of 56,886 tokens and the ACID corpus has a total of 55,78 o tokens.

\subsection{Corpus-based Critical Discourse Analysis}

As mentioned above, this study employs Wmatrix, an online corpus tool developed by Dr. Paul Rayson of Lancaster University, to conduct a textual analysis of the two corpora. The embedded Claws and USAS (UCREL Semantic Analysis 
System) can automatically perform parts of speech (POS) and semantic tagging (accuracy rates are $96-97 \%$ and $92 \%$, respectively). Key semantic areas in the observation corpus can be pinpointed by comparing with the embedded reference corpus (BNC Sampler Written is selected in this paper) (Rayson, 2008). The UCREL Semantic Tagset includes 21 broad semantic areas (A-Z), and each semantic field contains multiple sub-semantic domains, totalling 232 . The semantic area 'I: Money and commerce in industry', for example, can be divided into four subsections: 'I1: Money generally', 'I2: Business', 'I3: Work and employment' and 'I4: Industry'. The current paper aims to identify abnormal or overused semantic categories in the observation corpora (Log Likelihood $\mathrm{LL} \geq 6.63, \mathrm{p} \leq 0.01$ ), which will facilitate the analysis of thematic preferences and communication strategies at macro and meso levels. At the same time, this semantic tagging tool can generate a keyword list and parts of speech table, which will be analysed through a qualitative analysis of the concordance lines of high frequency words, so as to further reveal the micro-linguistic features of the two corpora. By using this corpus tool, therefore, it will be possible to compare the thematic preferences, communication strategies and microlinguistic features in the corporate profiles of Chinese and American banks, so as to effectively explore the types of corporate identities that are discursively constructed, thus providing a response to the above three-dimensional analytical approach.

\section{Findings}

\subsection{Analysis of Thematic Preferences}

By using the semantic tagging tool Wmatrix, the top 20 semantic fields that are communicated in the Chinese and American corporate profiles are firstly compared, with common and unique semantic fields being given in Table 1 and Table 2, respectively. Then frequent word families and concordance lines in each semantic area are analysed to highlight the similarities and differences in the preferred communicated themes of the Chinese and American banks. As shown in Table 1, the five semantic categories of I1 [Money generally], I2.1 [Business: Generally], I1.1 [Money and pay], I2.2 [Business: Selling] and A5.1 + + + [Evaluation: Good] head the list in the Chinese corporate identity discourse corpus, and are similarly salient in the American corpus, as might be expected, introducing basic business information about the corporations and answering the question of 'who am I?'.

As shown in Table 1, there is some degree of similarity between the lists created from the Chinese and American corpora. However, the rankings of these 
TABLE 1 Common semantic areas and high frequency words in Chinese and American corporate identity discourse

Common semantic

CCID

ACID

areas

\begin{tabular}{|c|c|c|c|c|}
\hline & Ranking & $\begin{array}{l}\text { High frequency } \\
\text { words }\end{array}$ & Ranking & $\begin{array}{l}\text { High frequency } \\
\text { words }\end{array}$ \\
\hline I1: Money generally & 1 & banks, financial, cash & 9 & $\begin{array}{l}\text { financial, bank, } \\
\text { insurance }\end{array}$ \\
\hline $\begin{array}{l}\text { I2.1: Business: } \\
\text { Generally }\end{array}$ & 2 & $\begin{array}{l}\text { business, financial } \\
\text { service }\end{array}$ & 1 & $\begin{array}{l}\text { business, financial } \\
\text { service }\end{array}$ \\
\hline I1.1: Money and pay & 3 & $\begin{array}{l}\text { asset, investment, } \\
\text { capital }\end{array}$ & 6 & $\begin{array}{l}\text { investment, } \\
\text { shareholder }\end{array}$ \\
\hline $\begin{array}{l}\text { I2.2: Business: } \\
\text { Selling }\end{array}$ & 4 & $\begin{array}{l}\text { customer, market, } \\
\text { transaction }\end{array}$ & 3 & $\begin{array}{l}\text { client, customer, } \\
\text { market }\end{array}$ \\
\hline $\begin{array}{l}\text { A } 5 \cdot 1+++ \text { : } \\
\text { Evaluation: Good }\end{array}$ & $5,7,19$ & best, excellent, top & 19 & $\begin{array}{l}\text { best, excellent, } \\
\text { greatest }\end{array}$ \\
\hline S8 +: Helping & 9 & service, support & 2 & help, serve \\
\hline $\begin{array}{l}\mathrm{S}_{5}+: \text { Belonging to a } \\
\text { group }\end{array}$ & 10 & branch, group & 5 & community, team \\
\hline A1.8+: Inclusion & 16 & $\begin{array}{l}\text { comprehensive, } \\
\text { include }\end{array}$ & 10 & inclusion, include \\
\hline
\end{tabular}

semantic categories differ and the concordance lines of high frequency words in each semantic area are also found to be different. For example, the semantic area A5.1 + + + [Evaluation: Good] appears more frequently in Chinese banks (ranking $5^{\text {th, }} 7_{\text {th }}$ and 19th respectively), while ranking 19th in the American corpus. Under this semantic tag, popular words are superlative adjectives, such as 'best', 'excellent' and 'great', that are used to describe the 'industrial status' of the banks (see Example 1), which is the most direct and positive construction of corporate identity.

Example 1. The Bank was awarded the title of the "Best Corporate Bank in China" by Global Finance ... (ICBC)

By comparison, Chinese banks use superlative adjectives more frequently, and tend to quote positive evaluations from third-party organisations (such as industrial rankings and awards) to prove their industrial status, thus highlighting their competitiveness. This evidence-based narration makes their identity 
construction more reliable (Wu and Zhang, 2019: 226). As summarised by Singh and Matsuo (2004: 866), the mention of awards and quality certifications that have been presented by international or local agencies is an online cultural marker of power distance. In terms of power distance, China's score (80) is twice that of America's (40) (Hofstede et al., 2010: 57). Influenced by the culture of high power distance, Chinese banks are more likely to indicate their industrial leadership and corporate competence in providing financial services.

The semantic area S8 + [Helping] is mainly accounted for by the frequent presence of words such as 'service', 'support' and 'help' to illustrate the corporate social concern being exercised. Table 1 shows that both Chinese and American banks prefer to portray themselves as service providers by describing their corporate services and social activities (Liu and Wu, 2015). By comparison, this semantic area is more salient in American corporate self-representation, ranking 2nd, while ranking 9 th in the Chinese corpus. This finding is in keeping with previous studies. For example, Shi and Shan (2019: 77) identified the prominence of the semantic category 'Helping' on the official websites of American financial companies. Interpreted from a cultural perspective, such phenomena can be attributed to the higher Uncertainty Avoidance Index (UAI) in the United States than in China (46 compared to 30) (Hofstede et al., 2010: 194). As Example 2 shows, American banks are more inclined to communicate their high quality service to reassure customers about their reliability and to eliminate their customers' perception of risk.

Example 2. We responsibly provide financial services that enable growth and economic progress. (Citi Bank)

Similarly, in the common semantic area $\mathrm{S}_{5}+$ [Belonging to a group], differences are found in the high frequency words and concordance lines of the Chinese and American corpora. Chinese banks prefer to use lexical terms that are related to branch and group to stress the corporation's business scale and strength, as shown in Example 3. In the American corpus, this semantic area is dominated by the notions of 'community' and 'team'. American banks tend to indicate their social roles and contributions to communities on the one hand (see Example 4), and to value the team spirit of their employees on the other hand (see Example 5).

Example 3. The Bank ... smoothly rolled out the systems of ICBC Mexico, Zurich Branch and Prague Branch. (IСBC)

Example 4. We are investing \$150 million on community grants and support to help more Americans. (Capital One) 
Example 5. Our team members are our most valuable resource. (Wells Fargo)

For the semantic area A1.8 + [Inclusion], the high frequency word 'comprehensive' collocated with 'comprehensive strategy/risk management' presents corporate strategy, risk management and control ability. However, in the American corpus, a frequently occurring concept is 'Diversity \& Inclusion', which appears a total of 48 times. The emphasis here is on corporate inclusivity and cultural diversification in an attempt to show care for employees. This can be attributed to the individualistic culture of the United States (Hofstede et al., 2010: 97), which leads American banks to value individual interests more than their Chinese counterparts.

In summary, although some common semantic areas are found in the discourse used in the corporate profiles of Chinese and American banks, there are some differences in terms of specific high frequency words and collocations. Chinese corporations tend to communicate 'industrial status', 'business distribution' and 'risk control' to highlight their corporate strength. However, American corporations attach importance to demonstrating corporate social responsibilities such as 'social service', 'community contribution' and 'multiculturalism'.

Besides the common semantic areas discussed above, there are several unique semantic categories in the two comparable corpora (see Table 2). A detailed analysis of high frequency words and concordance lines in each semantic area shows that Chinese banks prefer to communicate their development process, materialised in the sematic areas $\mathrm{N}_{1}$ [Numbers], A2.1 + [Change] and T2 + [Time: Beginning]. As shown in Example 6, a corporate history is often presented by Chinese banks to reflect their corporate capabilities. In traditional Chinese culture, a long corporate history is an indication of the strength of an enterprise. Another semantic area, S7.1 + [In power], is prominent in the Chinese corpus, which demonstrates how the organisational structure (see Example 7) can be used to construct an authoritative identity. This phenomenon can again be attributed to the high power distance of Chinese culture (Hofstede et al., 2010), which emphasises social status, management level and authority.

Example 6. Industrial and Commercial Bank of China was established on 1 January 1984. (ICBC)

Example 7. Currently, the Bank's Board of Directors is composed of 17 directors, including ... (Bank of Communications)

As shown in Table 2, unique semantic areas in the American corpus include I3.1 [Work and employment: Generally], A6.3 + [Comparing: Varied], L1 + [Alive], 
TABLE 2 Unique semantic domains and high frequency words in Chinese and American corporate identity discourse

\begin{tabular}{|c|c|c|c|c|c|}
\hline Chinese banks & Ranking & $\begin{array}{l}\text { High frequency } \\
\text { words }\end{array}$ & American banks & Ranking & $\begin{array}{l}\text { High frequency } \\
\text { words }\end{array}$ \\
\hline N1: Numbers & 8 & 2018, billion & $\begin{array}{l}\text { I3.1: Work and } \\
\text { employment: } \\
\text { Generally }\end{array}$ & 7 & $\begin{array}{l}\text { employees, } \\
\text { workplace }\end{array}$ \\
\hline A2.1 +: Change & 11 & $\begin{array}{l}\text { development, } \\
\text { reform }\end{array}$ & $\begin{array}{l}\text { A6.3 +: } \\
\text { Comparing: } \\
\text { Varied }\end{array}$ & 11 & diversity, variety \\
\hline M7: Places & 15 & international & L1 +: Alive & 14 & life, lives \\
\hline$S_{7 \cdot 1+:}$ In power & 17 & board, committee & A15 -: Danger & 17 & risk \\
\hline $\begin{array}{l}\text { T2 +: Time: } \\
\text { Beginning }\end{array}$ & 18 & establish, set up & W5: Green issues & 18 & $\begin{array}{l}\text { environment, } \\
\text { conservation }\end{array}$ \\
\hline $\begin{array}{l}\text { A13.2: Degree: } \\
\text { Maximizers }\end{array}$ & 20 & most, total & N3.2 +: Size: Big & 20 & growth, big \\
\hline
\end{tabular}

$\mathrm{W}_{5}$ [Green issues], etc. The first two semantic domains stress care for employees in two respects: the working environment and corporate culture (see Example 8). High frequency words in L1 + [Alive], 'life' and 'lives', on the one hand demonstrate cultural inclusiveness and diversity (such as a wide variety of life experiences) and, on the other hand, present the vision of improving the quality of life for customers, employees and local communities (such as making life better for ...). The semantic area $\mathrm{A}_{15}$ - [Danger] is used primarily to stress the attention paid by American banks to potential risks and their ability to control these risks, with high frequency phrases such as 'social/environmental risk' and 'risk assessment/management/reduce'. N3.2 + [Size: Big] is salient for presenting 'corporate business scale' and 'development history', which is comparatively less common in the American corpus, being ranked 20 th.

Example 8. We value our differences and work together to create a diverse and inclusive workplace where everyone can contribute to the success of our company. (PNC)

In addition, American banks also highlight 'environmental protection' (see Example 9) (materialised in $W_{5}$ [Green issues], ranked 18th), while this semantic area is less visible in the Chinese corpus (ranked 84th), which shows that 
American banks pay more attention to emphasising their awareness of environmental protection and sustainable development.

Example 9. We work hard every day to address the environmental challenges our planet faces in ways that will create long-term value for Fifth Third Bank. (Fifth Third Bank)

In summary, in keeping with common semantic domains, the above-mentioned unique semantic areas and high frequency words also reflect different thematic preferences in the self-representations of Chinese and American banks, which could be due to cross-cultural differences. Influenced by the high power distance culture of China, Chinese banks tend to highlight their 'development history' and 'organisational structure' and construct an authoritative identity by emphasising their long history and hierarchical management structures. In comparison, influenced by the individualistic and low power distance culture of the United States, American banks attach more importance to individual development and needs, and highlight corporate social responsibilities, such as care for employees, cultural diversification, environmental protection and community contribution, to construct a responsible identity.

\subsection{Analysis of Communication Strategies}

From the perspective of corporate communication strategies (Kim and Rader, 2010), both Chinese and American banks communicate corporate ability and corporate social responsibility related information. It is apparent that banks in both countries adopt a hybrid communication strategy, but their focuses are different. As for their corporate ability strategy, the sampled banks illustrate their industrial status in similar ways, with A5.1 + + + [Evaluation: Good] being salient. In this semantic area, the superlative adjectives 'best' and 'excellent' are used by both banks to stress corporate competitiveness. However, semantic categories and high frequency words related to corporate ability are more prominent in the Chinese corpus (see Table 1). Of the top 20 semantic areas in the Chinese corpus, only one, S8 + [Helping], is used to communicate corporate social responsibility, while the other semantic areas are all used to illustrate corporate capability. Thus, it can be seen that Chinese banks focus on demonstrating their corporate strength by making credibility appeals (Liu and Wu, 2015), in an attempt to win the public's trust. Even the lower-ranked semantic areas, $57.1+[$ In power] and T2 + [Time: Beginning], are used to index organisational structure and development history in an attempt to stress corporate ability, since in a high power distance culture, a clear hierarchical management structure and long corporate history are symbols of corporate strength. 
Although American enterprises also present corporate ability related information, relevant expressions are not prominent and their focuses are different. Comparatively speaking, American banks pay more attention to constructing soft power, such as 'risk management and control' and 'corporate culture'. For example, in the semantic area A15 - [Danger], 'risk' is found to be a high frequency word. This word aims to index corporate risk management and control ability through the phrase 'managing risk well' and to stress corporate awareness of internal risk through the phase 'risk is inherited'.

In comparison to Chinese banks, American banks prefer to adopt a corporate social responsibility strategy in their self-representations. They tend to show their care for multiple stakeholders with semantic areas related to employees, communities and environmental protection. For example, the semantic areas A1.8 + [Inclusion] and A6.3 + [Comparing:Varied] are salient for illustrating the inclusive and diversified culture of American banks. The prominent semantic areas I3.1 [Work and employment: Generally], $\mathrm{S}_{5}+$ [Belonging to a group] and $\mathrm{W}_{5}$ [Green issues] are used to construct American banks as caring for employees, serving the community and protecting the environment, in an attempt to win the public's trust through affective appeals (Liu and Wu, 2015). In comparison to American banks, Chinese banks communicate less information related to corporate social responsibility, which validates the findings of cross-cultural research on Chinese and American corporate websites by Shi and Shan (2019). Thus, there is still room for improvement in terms of elaborating on social responsibility information in Chinese corporate publicity discourse.

In summary, at the meso level, it is found that Chinese banks tend to adopt a corporate ability strategy to highlight their strength and to construct their identities as 'industry leaders' with long histories and hierarchical management structures. By comparison, American banks prefer to adopt a corporate social responsibility strategy and to construct themselves as 'social contributors' who care for their employees, serve their communities and protect the environment.

\section{$4 \cdot 3$ \\ Analysis of Micro-linguistic Features \\ 4.3.1 High Frequency Words}

According to the word list generated by Wmatrix, the top ten high frequency words in the Chinese corporate identity discourse corpus include 'bank', 'financial', 'China', 'management', 'business', 'customers', 'rank', 'Chinese', 'comprehensive' and 'best', while the top ten high frequency words in the American corpus are 'our', 'we', 'communities', 'employees', 'clients', 'diversity', 'business', 'financial', 'customer' and 'corporation'. The most frequent words in both corpora are self-referential words. Address forms are the most obvious sign of 
identity (Chen, 2014). Chinese banks tend to address themselves as 'the bank' to maintain distance between themselves and their customers and to indicate their respect for their customers through the use of impersonal and more formal expressions (Liu and $\mathrm{Wu}, 2015$ ). At the same time, it helps to construct their own authoritative identity. American banks often use 'we' and 'our' in self-reference to construct an internal group identity, personifying the corporation in an attempt to reduce the distance between themselves and the public (Liu and $\mathrm{Wu}, 2015$ ) and to create a sense of affinity. This finding contradicts Wu and Zhang's (2019) research on corporate annual report discourse. They found that Chinese companies prefer to construct their identity as being that of a friend who has a close relationship with the public, while American banks focus on the construction of an authoritative identity. This contradiction may be due to the different types of companies that were examined in these two studies. Most Chinese state-owned banks have an abundance of funds, attach more importance to maintaining an authoritative position when constructing their corporate identities and tend to use more formal and impersonal communication styles.

In addition, Chinese banks often use words that are related to the country (such as 'China' and 'Chinese'), while American ones do not. Interpreted from a cultural perspective, China is a collectivistic culture (Hofstede et al., 2010: 97) and attaches significant importance to collective interests. Therefore, Chinese enterprises pay more attention to showing affiliation to the nation and demonstrate a readiness to follow national policies (see Example 10).

Example 10. In response to the national macro policy of economic development, Hua Xia Bank matches financial services with customers' demand ... (Hua Xia Bank)

Only one stakeholder, the customers, is mentioned in the top ten high frequency words in the Chinese corpus. Other high frequency words, such as 'comprehensive' and 'management', aim to present corporate strategy. 'Rank' and 'best' are used to describe 'industrial status', which once again proves that Chinese banks tend to use numbers and rankings to present their corporate ability. American banks introduce a variety of stakeholders in their self-representations, including 'communities', 'employees', 'clients' and 'customers'. The word 'diversity' is frequently used to present a diversified and inclusive corporate culture and to stress care for their employees. These high frequency words further support the above analysis of thematic preferences and communication strategies at macro and meso levels, namely, American banks prefer to communicate corporate social responsibility and to construct their identity as that of 'social contributors'. 


\subsubsection{Parts of Speech (POS)}

Observing the Pos distribution table generated by Wmatrix, it can be seen that Chinese and American banks often use positive evaluative words, such as general superlative adjectives (JJT) and superlative general adverbs (RRT) to construct their corporate identities, confirming that companies favour a positive introduction in their corporate profiles, which is consistent with van Dijk's (2000) claim that "the general communication strategy of ideological discourse is usually positive self-presentation" (p. 44). In addition, cardinal numbers (MC) and numeral nouns (NNO) appear frequently in the Chinese corpus: these are used by banks to legitimise their statements on corporate 'development history' and 'business scale' in order to enhance their credibility. First person plural subjective personal pronouns (PPIS2) and possessive pronouns (APPGE) often appear more frequently in the American corpus, for example 'we', 'your' and 'our', and these pronouns make the communication more dialogic in nature. This finding corresponds to Wang and Bu's (2018) research on corporate annual report discourse, which found American corporate discourse to be more interactive.

Subsequently, the current study pays particular attention to the high frequency verbs that are used in the American and Chinese corpora (see Table 3). Verbs can be used to index corporate behaviours and activities. As Table 3 shows, Chinese banks frequently use the verb 'has (VHZ)' to present their abundant resources or to show corporate achievements in perfect tense. According to the six types of processes in the Transitivity System described by Halliday and Matthiessen (2004:170), 'has (VHZ)' is often used in the possessive process of relational processes, that is, this carrier has certain attributes, which can endow it with various resources. Therefore, Chinese banks tend to construct their identity as that of 'industry leaders' by describing their own possessions and achievements. However, American banks tend to use the base forms of lexical verbs (VVo) more widely, with the majority of them being active performative verbs. As active performers, American banks tend to construct their identity as that of 'social contributors' by describing specific activities (Liu and Wu, 2015). Similarly, the ING-participle forms of lexical verbs (VVG) that are used by American banks belong to positive performative verbs, such as helping' and 'providing'. In addition to describing corporate services, Chinese banks also use the continuous tense of verbs, such as 'representing an increase ...', 'ranking', 'operating' and 'admitting to the rule ...' to demonstrate their corporate ability from the perspectives of corporate performance, industrial status, business scope and values. Verbs that describe specific corporate activities are seldom used by Chinese banks. In that sense, differences also exist in the verbs used by Chinese and American banks. Chinese banks tend to stress their own capabilities while American banks emphasise their social contributions, 


\begin{tabular}{llll}
$\begin{array}{l}\text { Chinese corporate } \\
\text { profiles }\end{array}$ & $\begin{array}{l}\text { High-frequency } \\
\text { verbs }\end{array}$ & $\begin{array}{l}\text { American corporate } \\
\text { profiles }\end{array}$ & $\begin{array}{l}\text { High-frequency verbs } \\
\text { VHZ (has) }\end{array}$ \\
\hline has & VVo & $\begin{array}{l}\text { serve, work together, } \\
\text { help, support, deliver, } \\
\text { strive } \\
\text { providing, helping, } \\
\text { bVG }\end{array}$ \\
& $\begin{array}{l}\text { representing, } \\
\text { providing, } \\
\text { covering, oper- } \\
\text { ating, adhering, } \\
\text { ranking }\end{array}$ & VVG & $\begin{array}{l}\text { working, delivering, } \\
\text { lending }\end{array}$ \\
& & \\
& & & \\
& &
\end{tabular}

which confirms the analytical results obtained for thematic preferences and communication strategies.

In summary, in terms of micro-linguistic features, Chinese banks often use the phrase 'the bank' to refer to themselves and high frequency words such as 'comprehensive', 'rank' and 'best' to show their corporate capabilities in a formal and official communication style. In contrast, American banks prefer a dialogic communication style, using more self-references such as 'we' and 'our' to narrow the distance between themselves and the readers, and they are more likely to show concern for various stakeholders such as employees and their communities in their self-representations, to reflect their corporate social responsibilities. In addition, in terms of parts of speech distribution, banks in both countries tend to use positive evaluative adjectives and adverbs to positively construct their identities. As far as verbs are concerned, Chinese banks often use 'has', 'representing' and 'ranking' to highlight their strong corporate assets, performance and status; however, American banks prefer verbs like 'helping', 'providing' and other positive performative verbs to communicate their corporate social contributions.

\section{5}

\section{Conclusion}

With the assistance of the corpus tool Wmatrix, in conjunction with the threedimensional analytical framework of the discourse-historical approach, this paper conducts a comparative analysis of the corporate profile discourse of Chinese and American banks, respectively, from three perspectives: thematic 
preferences at the macro level, communication strategies at the meso level and linguistic features at the micro level. Many similarities and differences are found in Chinese and American corporate identity discourse. The discursive features at each level are not independent, but are related to one another, which jointly construct, negotiate and interpret corporate identities. This study explores the corporate identity discourse of Chinese and American banks from the perspective of social constructivism, which enriches research on institutional identity discourse, and also verifies the effectiveness and theoretical value of this theoretical framework.

Besides, this study explores the similarities and differences between Chinese and American corporate identity discourse in terms of linguistic features, communication strategies and identity types from a cross-cultural perspective, and confirms the influence of culture in the mutual construction of identity and discourse. The manifestation of this influence on the discursive features at different levels has been revealed. The research findings remind academics, and even industrial professionals, of the importance of cultural adaptation when vigorous efforts are being made to improve the international communication capability of Chinese companies.

Also, this study reminds us that although English is the medium used by Chinese companies for publicity discourse, English versions of Chinese corporate profiles still reflect typical Chinese cultural characteristics, for example, power relations are clearly communicated. However, in international communication, an effective measure is to understand the differences between their own communication strategies and those of the target countries, and then to make adjustments accordingly, to improve the capability of international communication. Another suggestion for Chinese companies is to enhance the communication of their corporate social responsibilities to create a positive impression with international stakeholders.

In addition, this paper conducts multi-faceted analyses of American and Chinese corporate discourse and discusses its social function of identity construction by taking social and cultural backgrounds into consideration. The relevant findings could be informative for Business English teaching and may have implications for students learning about the discursive features of business discourse.

\section{Acknowledgement}

This article was translated from a Chinese articleJiyuyuliaoku de Zhong-Meiyinhang qiye-shenfen huanyu yanjiu 基于语料库的中美银行企业身份话语研究 
(A corpus-based discourse analytic study of Chinese and American corporate bank identities)" Xiandai waiyu 现代外语 o2:170-182. The translated manuscript was peer-reviewed after submission to Contrastive Pragmatics and the authors revised the contents following the Reviewers' insightful suggestions.

We would like to express our sincere gratitude to the editors and the anonymous reviewers for their constructive comments on earlier versions of this paper. Any remaining errors are on our own.

\section{References}

Baker, Paul. 2006. Using Corpora in Discourse Analysis. London: Continuum.

Balmer, John M. T., and Edmund R. Gray. 1999. Corporate identity and corporate communications: creating a competitive advantage. Corporate Communications: An International Journal 4(4): 171-176.

Böttger, Claudia, and Kristin Bührig. 2004. Financial communication, translation and text forms: A contrastive analysis of US-American and German letters to shareholders. In: Gouveia, Carlos A. M., Carminda Silvestre and Luísa Azuaga (eds), Discourse, Communication and the Enterprise: Linguistic Perspectives. Lisbon: Ulices - University of Lisbon Center for English Studies, 233-243.

Breeze, Ruth. 2018. Researching evaluative discourse in Annual Reports using semantic tagging. Ibérica 35(2): 41-66.

Bucholtz, Mary, and Kira Hall. 2005. Identity and interaction: A sociocultural linguistic approach. Discourse Studies 7(4-5):585-614.

Chai, Gaiying, and Hua Han. 2017. 政府商务外宣话语中矢系身份的人际语用研究 [An interpersonal pragmatic approach to relational identity construction in webbased governmental business publicity discourse]. 外语教学 Foreign Language Education 1: 49-54.

Chen, Jianping. 2016. 中外大学机构身份话语建构比较研究 [Comparative studies of the discursive construction of the institutional identities of Chinese and western universities]. 中国外语 Foreign Languages in China 4: 29-39.

Chen, Jianping. 2017. 中英美大学机构身份的话语建构策略比较 [A comparative study of the discursive construction strategies of the institutional identities of ChineseBritish-American universities]. 现代外语 Modern Foreign Languages 1: 24-36.

Chen, Xinren. 2014. 语用学视角下的身份研究: 䏌键问题与主要路径 [Current research on identity from the pragmatic perspective: Key issues and main approaches]. 现代外语 Modern Foreign Languages 5: 702-710.

Christensen, Lars Thøger. 2008. Corporate and organizational identity. In: Wolfgang Donsbach (ed.), The International Encyclopedia of Communication. Malden, MA: Blackwell, 1014-1019. 
Garzone, Giuliana Elena. 2004. Annual company reports and CEO's letters: Discoursal features and cultural markedness. In: Christopher N. Candlin and Gotti Maurizio (eds), Intercultural Aspects of Specialized Communication. Bern: Peter Lang, 312-341.

Halliday, Michael A. K., and Christian M. I. M. Matthiessen. 2004. An Introduction to Functional Grammar. London: Arnold.

Hofstede, Geert, Gert Jan Hofstede, and Michael Minkov. 2010. Cultures and Organizations: Software of Mind. New York: McGraw-Hill.

House, Juliane. 2011. Linking constructions in English and German translated and original texts. In: Svenja Kranich, Viktor Becher, Steffen Höder and Juliane House (eds), Multilingual Discourse Production. Amsterdam: Benjamins, 163-181.

Kim, Sora, and Scott Rader. 2010. What they can do versus how much they care: Assessing corporate communication strategies on Fortune 5 oo web sites. Journal of Communication Management 14(1): 59-80.

Liu, Ming, and Doreen Wu. 2015. Discursive construction of corporate identity on the web: A glocalization perspective. Intercultural Communication Studies XXIV (1): 50-65.

Lu, Jingjing. 2019. 基于 Wmatrix 的中美药企网站企业概况文本对比研究 - 兼论“创译” 策略下的商务文本英译 [A Wmatrix-based contrastive analysis of the English versions of Chinese and American pharmaceutical companies' websites]. 上海翻译 ShanghaiJournal of Translators 1: 63-69.

Melewar, T. C. 2003. Determinants of the corporate identity construct: A review of the literature. Journal of Marketing Communications 9(4): 195-220.

Moura, Francisco Tigre, Singh Nitish and Wootae Chun, W. 2016. The influence of culture in website design and users' perceptions: Three systematic reviews. Journal of Electronic Commerce Research 17(4): 312-339.

PAD Research Group. 2016. Not so 'innocent' after all? exploring corporate identity construction online. Discourse \& Communication 10(3): 291-313.

Pollach, Irene. 2005. Corporate self-presentation on the WWW: Strategies for enhancing usability, credibility and utility. Corporate Communications: An International Journal 10(4): 285-301.

Rayson, Paul. 2008. From key words to key semantic domains. International Journal of Corpus Linguistics 13(4): 519-549.

Shi, Xingsong, and Xiaohui Shan. 2019. 基于语料库探讨中国企业英文网站的跨文化 适应水平 [A corpus-based study of the linguistic and cross-cultural adaptation of Chinese corporate websites]. 中国外语 Foreign Languages in China 2: 71-8o.

Singh, Nitish, and Hisako Matsuo. 2004. Measuring cultural adaptation on the web: A content analytic study of U.S. and Japanese web sites. Journal of Business Research $57(8): 864-872$.

Stryker, Sheldon. 1987. Identity theory: Developments and extensions. In: Krysia Yardley, and Terry Honess (eds.), Self and Identity: Psychosocial Perspectives. New York: Wiley, 89-103. 
Sun, Ya, and Jinlin Jiang. 2014. Metaphor use in Chinese and US corporate mission statements: A cognitive sociolinguistic analysis. English for Specific Purposes 33(2): 4-14.

van Dijk, Teun A. 2000. Ideology and Discourse: A Multidisciplinary Introduction. (English Version of an Internet Course for the Universitat Oberta de Catalunya) (UOC). London: Sage.

Wang, Lifei, and Han Bu. 2018. 中美企业话语的功能特征多维对比研究 [A multidimensional contrastive analysis of the functional features of Chinese and US corporate discourse]. 解放军外国语学院学报 Journal of PLA University of Foreign Languages 2: 96-103.

Wodak, Ruth. 2001. The discourse-historical approach. In: Ruth Wodak, and Michael Meyer (eds.), Methods of Critical Discourse Analysis. London: Sage, 63-94.

$\mathrm{Wu}$, Nan, and Jingyuan Zhang. 2019. 中美企业机构身份的话语建构策略 [Discursive strategies for the construction of Chinese and American corporate identities]. 现代外语 Modern Foreign Languages 2: 220-230. 